\title{
La paradiplomacia de Nuevo León: un estudio de caso
}

\author{
LUZ ARACELI GONZÁLEZ URESTI*
}

Artículo recibido: 29 de abril de 2015

Artículo aprobado: 22 de septiembre de 2015

Doi: dx.doi.org/10.12804/desafios28.1.2016.05

Para citar este artículo: González Uresti L. A., (2016). La paradiplomacia de Nuevo León: un estudio de caso. Desafíos, 28(I), 203-246. Doi: dx.doi.org/10.12804/desafios28.1.2016.05

\section{Resumen}

El análisis de la dinámica mundial exige, cada vez más, incorporar el estudio de los llamados nuevos actores y factores que dan sentido a los procesos del mundo contemporáneo. En este tenor se inscribe la paradiplomacia, actividad que cobra día a día mayor importancia al facultar a las entidades subnacionales a gestionar e implementar una agenda internacional acorde a sus necesidades y requerimientos. Este trabajo reflexiona, teóricamente, sobre sus alcances y límites, para posteriormente presentar el caso del estado de Nuevo León, México, en la administración de José Natividad González Paras, por tratarse de una experiencia que ejemplifica de manera amplia sus alcances y oportunidades como mecanismo, no sólo de vinculación con el exterior, sino porpromover proyectos conjuntos transfronterizos, como lo fue la iniciativa con los gobiernos del noreste mexicano y Texas, entre otros que se comentan en este estudio. Palabras clave: Paradiplomacia, entidades subnacionales, transfronterizo, soberanía, estados región.

\footnotetext{
* Profesora-investigadora y directora del Departamento de Relaciones Internacionales y Ciencia Política del Tecnológico de Monterrey, México. Doctora en Relaciones Internacionales por la Universidad Nacional Autónoma de México. Miembro del Sistema Nacional de Investigadores del CONACYT-México. Ha publicado varios trabajos sobre aspectos teóricos de las relaciones internacionales, política internacional y exterior de México. Correo electrónico: laguresti@itesm.mx
} 


\title{
The Paradiplomacy of Nuevo Leon: A Case Study
}

\begin{abstract}
An analysis of global dynamics increasingly requires the incorporation of the study of so-called new actors and factors that give meaning to these processes in the contemporary world. In this sense, paradiplomacy, an activity that is increasingly more important in world affairs, is necessary in order to empower subnational entities to manage and implement an international agenda for the needs of their respective region. This article analyzes the practice of paradiplomacy, and its limits, through the case of Nuevo León, Mexico, during the administration of José Natividad González. Paras. During his administration, the international activity of Nuevo León was very high and it is an experience that exemplifies the scope and the opportunities of paradiplomacy as a mechanism not only to link with the outside, but to promote joint cross-borderprojects, e.g., with the governments of northeastern Mexico and Texas.
\end{abstract} Keywords: Paradiplomacy, subnational entities, cross-border activities, sovereignty, state-regions.

\section{A paradiplomacia de Nuevo León: um estudo de caso}

\begin{abstract}
Resumo
A análise da dinâmica mundial exige, cada vez, mais, incorporar o estudo dos chamados novos atores e fatores que dão sentido aos processos do mundo contemporâneo. Neste tenor inscreve-se a paradiplomacia, atividade que adquire dia a dia maior importância ao facultar às entidades subnacionais a gestar e implementar uma agenda internacional conforme a suas necessidades e requerimentos. Este trabalho reflete, teoricamente, sobre os seus alcances e limites, para posteriormente apresentar o caso do estado de Nuevo León, México, na administração de José Natividad González. Paras, por se tratar de uma experiência que exemplifica de maneira ampla a seus alcances e oportunidades como mecanismo, não só de vinculação com o exterior, senão por promover projetos conjuntos transfronteiriço, como ofoi a iniciativa com os governos do nordeste mexicano e texas, entre outros que se comentam neste estudo.

Palavras -chave: Paradiplomacia, entidades subnacionais, transfronteiriço, soberania, estados região.
\end{abstract}




\section{Introducción}

Hablar de paradiplomacia resulta cada vez más frecuente en los ámbitos no sólo académicos, sino de comunicación en general, contrariamente a lo que ocurría apenas hace un par de décadas. El dinamismo de las sociedades actuales, aunado a procesos de descentralización de las actividades públicas y el paulatino, pero sólido proceso de participación democrática ha conllevado a que los asuntos internacionales dejen de ser coto exclusivo de las entidades tradicionales, los Estados centrales, y sean cada vez más dominio de actores subnacionales, que si bien no reclaman siempre independencia ni soberanía, sí demandan un ejercicio más efectivo de sus atribuciones en materia internacional, dando paso al desarrollo de actividades paradiplomáticas más estructuradas e institucionalizadas.

La paradiplomacia supone, en principio, un nuevo ejercicio de las facultades en el terreno internacional de las entidades que constituyen a un Estado, sean éstas regiones, estados federados, provincias, intendencias, länders, o cualquier otro nombre que reciban de acuerdo al modelo político correspondiente. Sin embargo, el común denominador entre todas ellas es el hecho de referirse a entidades que dependen de un poder superior (estados soberanos); no obstante, sus propias constituciones les confieren la capacidad de llevar a cabo actividades de vinculación, negociación, hermanamientos, promoción, etc., más allá de las fronteras del Estado, dando así forma a esta dinámica que ha dado en llamarse paradiplomacia.

Si bien el ideal teórico supone que la paradiplomacia debe ser un proceso institucional, estructurado y normado tanto al interior de cada país, como con sus vínculos hacia el exterior, la práctica de la misma nos muestra que esto aún no ocurre y es más una actividad fuertemente ligada a la personalidad del liderazgo en turno. El caso del estado de Nuevo León, en México, resulta un ejemplo claro de esta aseveración, y las administraciones de Natividad González (20032009) y de Rodrigo Medina (2009-2015), son elocuentes en este sentido. En este trabajo nos enfocaremos básicamente a la administración de Natividad González que es considerada en muchos sentidos como 
un ejemplo de actividad paradiplomática, estrictamente ligada a un proyecto de inserción de Nuevo León en el ámbito internacional y que la administración subsecuente no ha dado la continuidad esperada, debido al enfoque de seguridad que marcó el sexenio.

Para entender esta problemática es necesario iniciar haciendo una reflexión epistemológica y conceptual sobre las relaciones internacionales. En efecto, uno de los principales retos que afrontan los estudios contemporáneos en el área es poder articular los conceptos y categorías necesarios para dar cuenta, de manera clara y sistemática, de los constantes cambios que experimenta la sociedad internacional. Es común escuchar que son cada vez más los temas presentes en las agendas mundiales, así como las entidades involucradas en ellos, lo que ha conducido a que los paradigmas clásicos se muestren insuficientes para explicar esta llamada 'nueva' realidad. Al mismo tiempo, las teorías articuladas a su amparo dejaron fuera de su reflexión asuntos que hoy se han ido posicionando de manera importante en el escenario mundial. Aunado a esto, los niveles de análisis los cuales se habían venido construyendo las explicaciones, han tenido que redefinirse, por lo que hemos pasado de enfoques marcadamente estatocéntricos a planos analíticos en los que ya no sólo el Estado y otros actores internacionales, como las organizaciones internacionales de carácter gubernamental y no gubernamental, han sido objeto de estudio, sino que además hemos tenido que enfrentar el imperativo de reflexionar sobre otras realidades de carácter trasnacional, supranacional y subnacional, en ámbitos que van desde lo local, lo nacional, hasta lo global pasando por lo regional.

En este escenario es justamente en el que identificamos una realidad que cada vez toma más fuerza en los asuntos internacionales, y que se escapa de la compresión de los enfoques tradicionales. La actividad internacional de entidades subnacionales ha venido ganando terreno en distintos países del orbe y, paulatinamente, se ha ido consolidando como expresión del protagonismo de actores, que si bien son gubernamentales, realizan una intensa actividad internacional en paralelo a las instancias tradicionales del Estado al que pertenecen, 
dando origen a un fenómeno en creciente desarrollo y consolidación: la paradiplomacia.

Algunos autores coinciden en señalar que este concepto surgió a mediados de la década de los setenta; no obstante, es en los años ochenta en los que despertará mayor interés, debido a la apertura de mercados en zonas llamadas periféricas. Sin embargo, serán los años noventa el escenario en el que la paradiplomacia va consolidándose como parte de los procesos de democratización y descentralización del Estado así como de la apertura de las economías y la intensificación de los procesos de globalización, mismos que coinciden con la llamada crisis del Estado en su concepción westfaliana tradicional.

Cabe destacar que si bien el tema de la paradiplomacia parece haber adquirido una relevancia significativa en épocas recientes, tanto ella como los temas con los que tiene relación, tales como la crisis del Estado-nación, la cooperación transfronteriza y la actuación de las llamadas unidades subnacionales han estado presentes desde hace ya varias décadas con distintos nombres, conceptos y modelos de análisis, pero todos ellos haciendo referencia a cuestiones o elementos que parecen comunes a los también llamados "problemas transoberanos"1 y a la dispersión del poder de Estado en su concepción clásica.

Bajo esta lógica, también hemos presenciado el surgimiento de zonas específicas o subregiones dentro de las fronteras estatales, lo que está dando como resultado la consolidación de regionalismos. Inclusive, los límites territoriales de los países se han visto rebasados por la conformación de estas áreas de cooperación, que han propiciado la creación de lo que Kenichi Ohmae (1997) llama Estados-región; así, la tendencia hacia las integraciones subregionales es más que evidente en distintas partes del mundo. Regiones como el norte de Italia, Baden-Wütenberg, Johore en Malasia, las islas de Riay en Indonesia y el Gran Triángulo del Crecimiento, que incluye las ciudades de Penang (Malasia), Medan (Indonesia) y Phuket (Tailandia) son claros

\footnotetext{
1 Para mayor información sobre este término de la llamada sociología internacional, véase trabajo de Maryann K. Cusimano (1999).
} 
ejemplos de procesos en los que la pérdida del centralismo clásico del Estado-nación como eje medular encargado de atender los asuntos de la agenda mundial se hace evidente, lo que ha traído como consecuencia todo un replanteamiento de los alcances e importancia del federalismo (Ohmae, 1997). En este contexto es que nos enfocaremos a analizar el rol de una de las entidades federativas que integran a los Estados Unidos Mexicanos: El estado de Nuevo León, ya que por sus características económicas e industriales, tuvo una destacada participación y liderazgo para la formulación e implementación de estrategias que buscaban avanzar hacia la evolución de un proyecto de integración subregional con los Estados de Coahuila, Tamaulipas y Texas, vía una efectiva actividad paradiplomática, proyecto que alcanzó importantes logros sin embargo careció de continuidad.

\section{La paradiplomacia y los Estados-región}

Aunque el protagonismo de entidades subnacionales y la actividad internacional desplegada por ellas en el escenario internacional se considera algo relativamente reciente como área de reflexión en los asuntos internacionales, su práctica tiene una larga historia que puede remontarse a la primera mitad del siglo XX en distintas regiones del mundo. Casos como las reformas constitucionales de Bélgica para dar a Flandes una relativa autonomía respecto al manejo de su agenda exterior, o en Australia, el activismo de Melbourne frente a Estados Unidos e Inglaterra, o la propia región del pacífico, así como el ya añejo movimiento de Québec en Canadá, que en ciertos momentos de su devenir han incluso planteado la posibilidad del separatismo, son hoy un claro ejemplo de entidades con una amplia experiencia en ejecutar su propia agenda internacional. A estos casos se pueden sumar las políticas de regiones chilenas y argentinas las cuales, al compartir extensas líneas fronterizas, tienen que generar un proyecto propio de interacción que va más allá de los planes de los gobiernos centrales así como el activismo internacional de varios gobernadores de Estados de la Unión americana, de los cuales 38 tenían más de 56 oficinas de representación internacional al arranque del actual siglo (Lecours, 2002). 
Estos casos y muchos más que se han sumado en épocas recientes son clara evidencia de la forma en que los Estados han venido modificando su estructura y funciones tradicionales dando paso, progresivamente, a prácticas paradiplomáticas y a la consolidación de actores internacionales con marcado protagonismo. No obstante estos múltiples y diversos ejemplos, hemos de señalar que la paradiplomacia, hace referencia, en palabras de Ivo Duchacek, a:

En ausencia de cualquier autoridad superior a las dos partes (cada una de las cuales permanece bajo la soberanía de sus respectivos Estados-nación), los procesos de toma de decisiones transfronterizas en una región no son, y no puede ser, democráticas y mayoritarias, sino necesariamente consensuales. Así, el término paradiplomacia parece el más adecuado, de hecho, el prefijo 'para', no sólo indica algo paralelo, sino también de acuerdo con el diccionario Webster, algo asociado en subsidiariedad o con capacidad adicional (Lecours, 2002, p. 17).

Este concepto de paradiplomacia se ha ido consolidando como resultado de las fracturas que experimentó el sistema internacional surgido después de la Segunda Guerra Mundial, cuyo fin se vivió con la conclusión de la Guerra Fría y la subsecuente crisis del Estadonación, además de las exigencias por dar respuesta a problemáticas tales como los retos ambientales, los flujos de refugiados, la migración, las cuestiones de salud, el SIDA, el tráfico de drogas, el terrorismo, el contrabando de materiales nucleares y las actividades criminales internacionales, al lado de la intensificación de los intercambios y la cooperación, todas las cuales desafían las ideas tradicionales acerca de la soberanía y las facultades de los actores internacionales para atenderlas, lo que ha dado por resultado la promoción de actividades y programas transfronterizos que, en algunos casos, están dando por resultado nuevas formas de integración subregional, como ocurre en el caso del noreste mexicano.

Cabe destacar que si bien un nutrido círculo de estudiosos restringen la actividad paradiplomática al quehacer de entidades políticas subnacionales, hay otra corriente de estudiosos que sostiene que ésta no 
puede ser circunscrita únicamente del ejercicio llevado a cabo por los gobiernos locales, ya que otros actores, entre los que se reconocen empresas y organizaciones de todo tipo, han venido generando mayores grados de actividad internacional, generalmente como respuesta a las necesidades no resueltas por sus gobiernos federales (Zeraoui, 2007b), y por la propia lógica de la globalización e interdependencia características del mundo actual.

La práctica de la paradiplomacia responde a una serie de factores entre los que destacan: 1) las causas producto de las condiciones al interior de los Estados y 2) las causas de origen externo al Estado, ambas pudiendo ser inspiradas por motivaciones económicas, político-institucionales, culturales e incluso obligatorias, de acuerdo a la realidad geográfica del mismo. ${ }^{2}$ De esta manera, es posible constatar que la paradiplomacia es una manifestación más, que viene a romper con la tan desgastada visión estatocéntrica de la teoría realista de inicios del siglo XX (Zeraoui, 2007b), puesto que reconoce de manera esencial la influencia de otro tipo de actores distintos a la tradicional figura del Estado en el manejo de las relaciones internacionales.

Otros autores identifican a la paradiplomacia como diplomacia no central o diplomacia paralela (Martínez, 2007). En suma el concepto paradiplomacia (en relación a las Entidades Federales) significa:

[...] la participación de los gobiernos no centrales en las relaciones internacionales, a través del establecimiento de contactos permanentes o ad hoc con entidades públicas o privadas extranjeras, con el propósito de promover diversos aspectos socioeconómicos o culturales, así como cualquier otra dimensión exterior de sus propias competencias constitucionales (Cornago, Noé, en Rodríguez, Sergio, 2006, p. 56).

\footnotetext{
2 Ver Moreno, Raquel. Dispónible en: http://www.sre.gob.mx/eventos/forogoblocales/ doc/raquelmor_uag.pdfhttp://www.sre.gob.mx/eventos/forogoblocales/doc/aquelmor. uag.pdf
} 
Según Francisco Aldecoa (2006), existen ciertas fuerzas motoras del quehacer de la paradiplomacia, las cuales de manera concreta son: 1) motivación económica; 2) motivación política; 3) motivación cultural; 4) motivación transfronteriza, y 5) motivación derivada de aspectos migratorios. Estas distintas motivaciones, a su vez, van acompañadas de acciones específicas, entre las que destaca los mecanismos de institucionalización de dicha actividad.

Los cambios derivados del fin del orden bipolar y la emergencia de los llamados 'nuevos' temas de la agenda mundial han sido, por una parte, el motor que ha impulsado la redefinición de las fronteras y alcances de las soberanías. Sin embargo, otro elemento fundamental que ha infundido nueva vida a todas las regiones y subregiones en el mundo ha sido la lógica de la economía global. Como lo menciona Kenichi Ohmae (2005), en su obra El próximo escenario global, "el desarrollo continuo de la economía global terminará por socavar al Estado-Nación y favorecerá la región. Esto representa un anatema para aquellos que creen que un Estado grande, centralizado, es la única vía para dirigir la política, la sociedad, la economía y la cultura" (p. 42). La noción clásica de la política internacional, donde el Estado es el actor clave por excelencia, ha decaído en las últimas décadas por la consolidación de otros actores en la escena internacional, tales como los grupos de presión, las organizaciones internacionales, los actores al margen de la ley y las empresas trasnacionales, por enumerar sólo algunos. Dado que las entidades estatales son incapaces de abarcar todo el espectro de tareas, a menudo son las regiones de los Estados las que se mueven hacia el exterior y las que trabajan y piensan desde una perspectiva verdaderamente global y sin fronteras, concibiéndose a los Estados no como monolitos políticos, sino como una amalgama de regiones (Ohmae, 2005).

En este escenario, el elemento económico (y el crecimiento de éste) se sobrepone al factor militar (clave a lo largo de la Guerra Fría), ya que la regionalización y el debilitamiento de las alianzas geoestratégicas impone a los Estados "la necesidad de localizarse en el espacio mundial, de redefinir su relación con la región, simple y sencillamente porque casi no existe otra mediación disponible entre lo nacional y 
lo mundial" (Ohmae, 2005, p. 68). Esta situación genera, en palabras de Ohmae (2005), "un mundo verdaderamente entrelazado e interdependiente, unido por una economía global" (p. 70). Además, dicha interdependencia entre países ha generado una competencia económica que en la actualidad es mucho más próxima, lo cual viene a afianzar esa misma situación mundial de entrelazamiento.

En esta misma línea, Paul Kennedy (1993) menciona que la lógica del mercado global "no presta atención al lugar en el que se hace un producto”. Es por ello que argumenta que "el estado-nación y su seguridad también se ven amenazados por la nueva división internacional de la producción y el trabajo" (p. 169), lo cual denota esa decadencia o crisis del Estado-Nación. En pocas palabras esta 'economía global' ha hecho que las fronteras nacionales sean mucho menos restrictivas que antes, por lo que cada día que pasa 'el mundo tiene menos fronteras'. De acuerdo con este mismo autor, todos estos cambios globales han puesto en duda la propia utilidad del Estado-nación:

$\mathrm{Al}$ parecer, el actor autónomo clave en los asuntos políticos e internacionales durante los últimos siglos parece estar no sólo perdiendo control e integridad, sino la clase equivocada de unidad para hacer frente a las nuevas circunstancias. En algunos problemas es demasiado grande para operar con eficacia; en otros, es demasiado pequeño. Por consiguiente, se producen presiones para una 'redistribución de la autoridad' tanto hacia arriba como hacia abajo, creando estructuras que podrían ser capaces de responder de modo más efectivo a las fuerzas actuales futuras a favor del cambio (Kennedy, 1993, p. 172).

En consecuencia, este contexto mundial ha consolidado el surgimiento de zonas específicas al seno de los propios Estados, debido a la mayor conexión y acercamiento entre estas 'subregiones' en términos económicos, políticos, financieros y culturales. Esta actividad socava los límites territoriales de los países, los cuales se han visto rebasados por la conformación de estas áreas de cooperación que Ohmae denominó como ‘los Estados-región’ o ‘regiones-Estado’. 
En la línea de Zaki Laïdi (1994), es por este surgimiento de subregiones que, para las sociedades, la regionalización obedece a la necesidad de sustraerse a la tutela del Estado-nación, de vivir la pluralidad de sus identidades y de ampliar la gama de sus preferencias, de sus gustos y de sus ligas. Laïdi agrega que es probable que una de las modalidades más fuertes de esta demanda de identidad pluralista y transnacional pase por la etnicidad. Por ejemplo, en América del Norte, la integración de México al espacio estadounidense sin duda alguna se facilitará gracias a cierta 'hispanización' de los Estados Unidos (Laïdi, 1994). Se nota aquí un factor que, más allá de la aspiración económica, conlleva a un proceso de interacción en el ámbito cultural, en la medida en que los flujos de personas entre las partes se han presentado casi como una característica sine qua non del proceso. Esta integración de México y Estados Unidos ha venido generándose sobre todo en las zonas fronterizas, en enorme magnitud por el abundante intercambio tanto en materia económica como social, y en gran medida también por la vinculación cultural. Este es el caso de la frontera del noreste de México, que se presentará más adelante.

Cabe señalar que uno de los factores clave del surgimiento de las subregiones en el ámbito internacional reposa en el papel de la industria, que en los últimos años tiene una orientación mundial cada vez más creciente. Las estrategias de las modernas corporaciones multinacionales ya no están inspiradas por razones de Estado, sino por el deseo de atender los mercados atractivos, independientemente del lugar donde estos tengan lugar. Por consiguiente, el elemento esencial en cualquier región floreciente debe ser una actitud de apertura hacia el exterior, ya que "el resto del mundo debe contemplarse positivamente, como la fuente de prosperidad". Esa apertura propicia que las industrias y los proveedores de servicios se vean atraídos, estableciéndose allí para apoyar a las otras industrias que encabezan la aceleración industrial. Cabe destacar, que según Ohmae, la noción de región-Estado no es una unidad política, sino económica, porque ésta, donde quiera que esté localizada, es el motor de la economía global (Ohmae, 2005).

Ohmae reconoce que entre las entidades que integran a las regiones suelen existir grandes disparidades de riqueza, lo cual sugiere que el 
Estado-región actúe de acuerdo a su existencia y a su importancia, es decir, de forma coherente, lo cual constituye la prueba de fuego del Estado-región. Por tal razón el único método razonable, sostiene Ohmae, consiste en planificar una estrategia y desarrollar una organización exclusivamente para la región, que permita establecer vínculos operativos y útiles. Esta estrategia es conocida como 'estrategia de la cebra' (Ohmae, 1997).

En materia económica, 'todos los Estados-nación son cebras', ya que los medios varían, las tasas de crecimiento cambian, al igual que la infraestructura, los gustos y la preferencia de los consumidores, entre otros. Esta hipótesis, presentada por Ohmae, sugiere que al trasladar estas variaciones y al dibujarlas en un mapa respecto de la región en la cual se pretende invertir, estas diferenciaciones, cuando se observan de cerca, hacen recordar el camuflaje de las cebras, ya que el color indudablemente no será uniformemente gris, en la medida en que habrá áreas de actividad oscuras separadas por espacios en blanco. Para la realización de la estrategia de cebra es necesario enumerar 'las listas de la cebra', lo cual no es otra cosa más que la elaboración de puntos de destino, ya que los gustos del consumidor son significativamente variables, aunado a la infraestructura, las tasas de crecimiento y las demás variables económicas. Además, es importante tener presente que "los Estados-nación suelen tener fronteras claramente delimitadas, los Estados-región no suelen tenerlas"; no obstante, "las 'soluciones' regionales serán unos instrumentos cada vez más potentes para superar a la competencia” (Ohmae, 1997), por lo cual es conveniente crear alianzas o empresas conjuntas transfronterizas, establecer empresas virtuales y aprovechar los diferenciales de costes de la mano de obra o de lo servicios (Ohmae, 1997).

De este modo, la regionalización y los procesos de subregionalización se han convertido en tendencias predominantes que contemplan un incremento en la interconexión e interdependencia entre Estados, entidades subestatales y sociedades en general. Es decir, cada vez son más comunes las imágenes de flujo global de dinero, personas, valores e ideas, lo que ha ayudado a superar el sistema de las barreras nacionales, las cuales aún buscan preservar la autonomía del Estado. 
De acuerdo con Hirch (1999), el aumento de la importancia de las relaciones interregionales es también una característica de la ola de globalización actual, por lo que el entendimiento tradicional de soberanía se ha venido socavando, ayudando a que las regiones individuales se vayan expandiendo dentro de un contexto global

Si bien se reconoce que la relación entre las partes integrantes de una región es importante por la necesidad de comunicación y cooperación entre las mismas, no se puede obviar la necesidad existente de la validez de los gobiernos para que el flujo cooperativo tenga bases sólidas en su núcleo, y no sólo se quede, por ejemplo, a nivel empresarial. Como señala Nye (Keohane \& Nye, 1989), se debe apuntar el concepto de cooperación regional intergubernamental, el cual se refiere a un proceso abierto, donde los Estados individuales actúan juntos para el beneficio mutuo en algunos campos, tales como infraestructura, agua y energía, y para resolver tareas en común (Hirch, 1999). Ejemplo de esto es la creciente cooperación entre Texas (EEUU) y Tamaulipas (México) en materia de sanidad e infraestructura, en torno al manejo y control del Río Bravo/Río Grande que comparten, generándose, incluso esquemas de cooperación interinstitucional transfronteriza. ${ }^{3}$ Esta situación se replica en otros ámbitos de la frontera México-Estados Unidos y se extiende a los Estados de Coahuila y Nuevo León, por lo que se puede señalar que la región noreste de México se halla en un claro y creciente proceso de interdependencia que bien parecía encaminarse a una integración subregional y cuyos mecanismos trascenderían las fronteras nacionales incorporando en el proceso al estado de Texas.

\section{La región noreste de México: el estado de Nuevo León y su liderazgo regional}

Aunque los procesos de integración en el mundo actual están dominados por los grandes bloques, como la Unión Europea, el TLCAN, y MERCOSUR entre otros, sus dimensiones y las propias contradic-

\footnotetext{
3 Ver coalición de la Cuenca Río Bravo/Río Grande, "Desarrollo Sostenible para la Cuenca del Río Grande/Río Bravo", 9 abril 2007 (http://www.rioweb.org/).
} 
ciones derivadas de ésta los han convertido en procesos sumamente lentos y fuertemente burocratizados, por lo que en paralelo hemos sido testigos de la emergencia de novedosas fórmulas de integración a nivel subestatal. Ya mencionábamos como ejemplos de esto los casos Baden-Würtemberg, en Alemania; el Triángulo del Crecimiento de Singapur; Johore en Malasia y su vinculación con las islas Riau en Indonesia, así como el Gran Triángulo del Crecimiento conformado por Penang (Malasia), Medan (Indonesia) y Phuket (Tailandia), de las que nos habla Ohmae en su libro El fin del estado-nación (1997), los cuales se inscriben dentro de la conformación de zonas subregionales de integración.

En este contexto, cada vez se hace más evidente la existencia de un proceso similar en la frontera noreste de México, ampliándose a Texas. Uno de los factores que han coadyuvado a que tal situación se presente en esta subregión lo constituye el aspecto geográfico, ya que los estados de Nuevo León, Tamaulipas, Coahuila (en México) y Texas (de en Estados Unidos) se encuentran inmersos en un espacio territorial de colindancia que ha propiciado que los elementos de coincidencia se vayan incrementando de manera gradual. ${ }^{4}$ Ante tal panorama, ya no sólo reina el espectro económico como el leitmotiv de la integración, sino que esta perspectiva ha consolidado la consideración de otras variables, tales como la seguridad, el medio ambiente, las comunicaciones, entre otras.

La frontera noreste de México ha sido testigo de un proceso de vinculación en diversos ámbitos que ha ocasionado un mayor acercamiento entre los sectores gubernamentales y empresariales de las tres entidades. La ventaja geográfica con la que se cuenta fue un factor detonante para el arranque de la iniciativa; sin embargo, más allá de este aspecto, en la región subyacen diversos elementos que propician que este proyecto cuente con verdaderas razones puntuales para su

\footnotetext{
4 El tema de la integración regional entre el noreste mexicano (Coahuila, Nuevo León y Tamaulipas) con el Estado de Texas fue ampliamente desarrollado en Monterrey, en particular durante el sexenio de Natividad González. Ver ITESM (1994); Farías Campero (2005) Gobierno del Estado de Nuevo León (2007).
} 
éxito. En la medida en que se cuenta con estructuras, medianamente similares en términos económicos, industriales, empresariales, educativos y sociales, que convergen en una red de complementación que ha dado lugar a esquemas de vinculación muy intensa no solo entre estas tres entidades, sino que se extienden más allá de las fronteras nacionales involucrando al estado de Texas, esto como producto de la propia evolución histórica de la zona. Sin embargo, este proceso fue fomentado en gran parte por el estado de Nuevo León, en la medida en que el propio jefe del ejecutivo estatal, José Natividad González Parás -cuya administración fue del 2003 al 2009- lo incluyó como parte de su plan de gobierno al reconocer que "el modelo de cooperación enfrentaba el reto de evolucionar con el fin de impulsar aún más el desarrollo integral de América del Norte y muy señaladamente el de subregiones como la conformada por los estados del noreste de México y el estado de Texas" (Gobierno del Estado de Nuevo León, 2004, p. 64).

Es innegable que para hacer frente a las transformaciones en la sociedad internacional existen actores dentro de la esfera nacional, tales como las entidades federativas, que buscan ser participantes activos de la dinámica mundial dentro de un contexto de complementación y cooperación mutua. En este sentido, el estado de Nuevo León durante el gobierno de Natividad González se caracterizó por su intento de construir diversos canales de comunicación, a través de los cuales fuese posible el surgimiento de acuerdos que dieran cabida a la materialización de un proyecto de integración subregional entre los Estados que conforman la zona. De esta manera, el principal promotor que fomentó la planificación de una estrategia puntual y desarrolló una organización exclusiva para esta subregión ha sido Nuevo León, gracias a la creación de diversas estructuras institucionales que reflejaban el interés del Estado para que tal proyecto se llevase a cabo.

Entre las principales acciones que se realizaron destaca el estatus que se le otorgó a este iniciativa dentro del Plan Estatal de Desarrollo, ya que se le catalogó como un proyecto estratégico que debía ser implementado para aprovechar las ventajas que tiene la vecindad con Texas y 
las entidades colindantes tanto al oriente como al poniente, es decir, Tamaulipas y Coahuila, respectivamente. En segundo lugar, tiene especial relevancia la creación de la coordinación del programa para la integración del desarrollo regional del noreste y su vinculación con Texas, que representaba la instancia encargada de formular las estrategias que había de implementarse para lograr un incremento de las relaciones entre las partes, fortaleciendo así la actividad paradiplomática del Estado, pues, recordando a Raquel Moreno (2007), entre los medios para llevar a cabo actos paradiplomáticos se encuentran las dependencias de fomento hacia el exterior, las misiones de promoción, los viajes al extranjero y la celebración de acuerdos, entre otros. Por otro lado, las estrategias incluyen el planteamiento de objetivos a mediano y largo plazo, el establecimiento de una agenda que incluya las acciones a realizar, así como la identificación de prioridades geográficas, la preferencia por actores especiales que ayuden a cumplir los objetivos planteados, la creación de un órgano capaz de sistematizar la relación con el exterior, la obtención del personal adecuado, la instrumentación de un medio de seguimiento y la evaluación del proyecto en el exterior, entre otros (Moreno, 2007). De esta manera se consolida lo que autores como Allison plantea en los modelos de Proceso Organizacional y de Política burocrática (Allison, 1988). Acciones todas éstas, implementadas en su momento por la administración de González Parás.

\section{El Plan Estatal de Desarrollo del estado de Nuevo León y la paradiplomacia}

El Plan Estatal de Desarrollo (PED) es, al igual que el Plan Nacional de Desarrollo (PND), un poderoso instrumento para plantear (al menos de manera formal) los objetivos, estrategias y líneas de acción de un gobierno en un periodo de tiempo determinado. El PED del gobierno de Nuevo León para el periodo 2004-2009 reflejó, sin duda alguna y de manera intencionada, una meta clara para el Estado en relación al ámbito de la paradiplomacia: la internacionalización de Nuevo León. Para ello, estableció de manera concreta un apartado titulado "Proyectos estratégicos para transformar Nuevo León". 
El primero de estos proyectos estratégicos fue la "Integración del proceso de desarrollo económico-regional de Nuevo León: el noreste de México y Texas." Este proyecto poseía como objetivo central alcanzar la integración de la región noreste de México con Texas, de modo tal que ésta pudiese constituirse en una zona de cooperación estratégica. Las acciones específicas que se llevarían a cabo para cumplir con el proyecto eran:

1) la creación de una Administración Pública Estatal y una Coordinación Ejecutiva que se encontrase a la cabeza del proyecto; 2) la creación de un Consejo dentro del cual participaran los gobernadores de Nuevo León, Coahuila, Tamaulipas y Texas, además de funcionarios y demás representantes académicos y empresariales; 3) la elaboración de un Convenio para el Desarrollo Integral Regional del Noreste de México; 4) el establecimiento de un equipo de Representantes Permanentes con miembros de los Estados involucrados; 5) el involucramiento de los gobiernos federales mexicano y estadounidense y de organismo financieros de carácter internacional; 6) el apoyo a Colombia (comunidad planificada fundada en 1992 en el municipio de Anáhuac, Nuevo León) y la creación de un nuevo polo de desarrollo al norte de Nuevo León; 7) el impulso comercial a través del Puente Colombia y los servicios de carga y ferrocarril en Nuevo León; 8) un mayor aprovechamiento del gas natural de la Cuenca de Burgos con énfasis en la prioridad medio ambiental; 9) la firma de un convenio de cooperación entre los gobiernos involucrados y Petróleos Mexicanos para establecer bases de explotación de la Cuenca de Burgos; 10) una mayor infraestructura en carreteras para conectar de forma más eficiente a Nuevo León con Tamaulipas y Coahuila; 11) el empleo del financiamiento para el Desarrollo de América del Norte; la promoción de inversiones conjuntas y acordes al TLCAN; 12) un mayor impulso a la investigación e inversión en tecnología; 13) llevar a cabo políticas públicas a nivel regional; y llevar a cabo actividades educativas, culturales, científicas, deportivas y sociales de manera conjunta (Gobierno de Nuevo León, 2004, pp. 154-156). 
El segundo proyecto estratégico era la "Consolidación de Monterrey como Ciudad Internacional del Conocimiento." Éste tenía cuatro objetivos centrales: promover el desarrollo tecnológico, proyectar a nivel internacional la gran calidad educativa, crear la infraestructura necesaria, e impulsar la competitividad gubernamental y privada. Dichos objetivos incluían a su vez las siguientes líneas de acción:

1)creación de un plan para llevar a cabo el proyecto en el corto, mediano y largo plazo; 2) identificación de áreas de conocimiento que tuviesen un mayor potencial para ser desarrolladas; 3) involucramiento del proyecto a nivel federal; 4) formalización, a través de un convenio, de las instituciones que participarán en el proyecto; 5) establecimiento de un Consejo en el que participaran las principales universidades de la región; 6) establecimiento de una Corporación para la Innovación y Competitividad de los Sectores Productivos; 7) fortalecimiento de la Coordinación para la Innovación y Competitividad Gubernamental del gobierno estatal; 8) firmar un acuerdo con la Secretaría de Educación Pública (SEP) y otras instituciones de educación media superior y superior para promover áreas de conocimiento; 9) firmar un acuerdo para involucrar a los Estados de Tamaulipas y Coahuila en el proyecto; 10) llevar a cabo actividades para la creación de centros de innovación y la creación de un parque del conocimiento; 11) impulsar la creación de un museo del conocimiento y tecnología; y 12) establecimiento de una agenda permanentes para conferencias, congresos y ferias de conocimiento (Gobierno de Nuevo León, 2004, pp. 158-159).

Además, el PED planteaba otros proyectos estratégicos en cuanto a vivienda popular, sistema de transporte colectivo y, de manera particular, la integración urbana del Parque Fundidora con el Barrio Antiguo y la Macroplaza (Gobierno de Nuevo León, 2004). Aunque estos proyectos no se encuentran directamente vinculados con el tema de la paradiplomacia, sí es posible vincularlos de manera indirecta, en el sentido de que buscan avanzar en la dirección de un mayor desarrollo del Estado que bien pudiera ser aprovechado en pro de la 
internacionalización del mismo ya sea para captar inversión extranjera o para promover el turismo nacional e internacional.

Cabe destacar que en otros apartados del PED se plasmaron objetivos adicionales que apuntaban a la promoción de una internacionalización cada vez más evidente de Nuevo León. Entre éstos se destacan la vinculación de Nuevo León con otras entidades federativas y la promoción de relaciones internacionales bajo una perspectiva futura; la generación de empleos y un crecimiento económico que reflejase el liderazgo del Estado a nivel nacional y regional; la promoción de inversión y exportaciones para la constitución de una región con proyección internacional, y el impulso del turismo a nivel regional, nacional e internacional (Gobierno de Nuevo León, 2004).

Ciertamente el protagonismo de Nuevo León, particularmente en lo relativo a su activa labor internacional se hizo evidente no sólo por lo expresado en su Plan Estatal de Desarrollo, sino por el despliegue de sus actividades paradiplomáticas; sin embargo, hay que señalar que esto, al igual que todos los asuntos relacionados al actuar de las Entidades Federativas del país, debía realizarse acorde a la Constitución Política de los Estados Unidos Mexicanos, ya que ésta plantea una serie de aspectos en relación a las facultades y atribuciones propias de los Estados y de las situaciones bajo las cuales éstos deben apegarse.

La Constitución fija ciertas limitaciones a las que están sujetas las entidades federativas, en relación al ámbito de los asuntos internacionales destacan las siguientes:

[...] los Estados no podrán celebrar alianza, tratado o coalición con otro Estado [país] ni con las Potencias extranjeras; acuñar moneda, emitir papel moneda...; gravar el tránsito de personas o cosas que atraviesen su territorio; prohibir... la entrada a su territorio, ni la salida de él, a ninguna mercancía nacional o extranjera; expedir leyes o disposiciones fiscales que importen diferencias de impuesto o requisitos por razón de la procedencia de mercancías nacionales o extranjeras; contraer... obligaciones o empréstitos con gobiernos de otras naciones, con sociedades 
o particulares extranjeros, o cuando deban pagarse en moneda extranjera fuera del territorio nacional[...] (Artículo 117) (Gobierno de Nuevo León, 2004).

En referencia al último punto es importante señalar que si bien los Estados no podrán recibir empréstitos de otras entidades externas, sí es posible realizar esfuerzos de cooperación económica del tipo que sucede en el bloque del noreste de México y Texas. En esta línea, vale la pena rescatar a Montaño (2003) cuando escribe que los retos de la globalización y la interdependencia no suponen el rechazo de estas disposiciones constitucionales, sino su adecuación a las realidades que se viven actualmente. También el nacionalismo histórico está sujeto a una revisión que permita reconocer la dimensión de los desafíos y el mejor interés nacional. Por tal razón, "el nuevo actor, a fin de entrar en escena, requiere de un libreto dinámico, capaz de asegurar una participación efectiva en la política exterior mexicana" (Montaño, 2003, p. 14).

En este marco constitucional los estados, y por ende el de Nuevo León, sin contravenir el espíritu de la Carta Magna, han incursionando cada vez más en la práctica de la paradiplomacia, que si bien ha existido a lo largo de la historia reciente, hoy en día ha adquirido dimensiones particulares, como resultado de los cambios mundiales entre los que destacan por su trascendencia el fin de la Guerra Fría y el reacomodo de fuerzas internacionales, aunado a los procesos de globalización e integración regional, y a la crisis del Estado Nación. No obstante, desde inicios de la década de los ochenta del siglo pasado, este término ya había sido empleado cuando se hacía "referencia a un nuevo fenómeno: la actividad exterior de las entidades regionales y locales" (Rodríguez, 2006, p. 36). Ejemplo de esto lo constituye el municipio de Monterrey (capital de Nuevo León), que en los años de la administración ya referida de González Parás, vino consolidando un rol de liderazgo al encabezar diversos eventos y proyectos de corte internacional, que fueron coadyuvando a su proyección fuera del país. Como ejemplos de esto se pueden referir, entre otros, la Conferencia Internacional sobre la Financiación para el Desarrollo, llevada a cabo en el año 2002, convocada por la ONU, y la Cumbre 
Extraordinaria de las Américas Monterrey, celebrada en enero del 2004, bajo los auspicios de la Organización de Estados Americanos (OEA), así como el haber sido Sede del Forum Universal de las Culturas, Monterrey 2007.

\section{Planes, acciones y estrategias del Estado de Nuevo León}

Ya desde 1994 se preveía que las megatendencias en el mundo impactarían a Nuevo León de manera tal que era necesario preparar los mecanismos por medio de los cuales se podrían enfrentar esas circunstancias. En ese año se determinaron tres estrategias globales para el Estado, las cuales fueron identificadas con base a la influencia que los cambios mundiales tendrían al interior de la entidad. Los planteamientos formulados en el Plan estatal de desarrollo fueron los siguientes: fortalecer la integración económica con el Estado de Texas, incrementar el valor agregado en los productos de los sectores tradicionales y desarrollar un sector de servicios de base tecnológica.

Destaca el hecho que desde la mitad de la década de los noventas ya se contaba con una visión a futuro en la cual se incluía el factor de integración como herramienta que propiciaría el progreso de la entidad. Sin embargo, no fue sino hasta la llegada de González Parás ${ }^{5}$ al gobierno del Estado, que se inició de manera sólida la materialización de aquellas iniciativas, a través de la puesta en marcha de una serie de planes y proyectos tendientes a impulsar los procesos de integración y vinculación entre las entidades de Coahuila, Tamaulipas y Texas, con la posterior integración de Chihuahua a partir del siguiente reconocimiento: "es evidente que los esfuerzos de los gobiernos estatales, locales y Federal han sido insuficientes para fortalecer la competitividad de México y la de sus regiones, como el noreste del país... si bien es importante impulsar las políticas públicas federales

\footnotetext{
5 González Parás no fue solamente un político, sino un académico que publicó varias obras referentes a la necesidad de otorgar más poder a las regiones. Entre estas se destacan González Parás, José Natividad. El fortalecimiento del pacto federal (1978) y Desconcentración, descentralización y división territoria (1982).
} 
que incidan en la competitividad de la zona, es igualmente importante poner gran énfasis en las acciones que los gobiernos locales y estatales de México y Estados Unidos puedan diseñar y ejecutar de manera coordinada, con estricto respeto a su soberanía, a efecto de disminuir los costos de transacción y fortalecer así las ventajas comparativas de la región"(Gobierno del Estado de Nuevo León, 2003). Esto no significa que México ha dejado de ejercer su potestad territorial al interior de las entidades, sino que más bien parecieran confluir dos posibilidades: que el modelo de intervención gubernamental al interior de los estados se ha agotado en la medida en que éstos ahora exigen mayores atribuciones; y/o que los estados ya no pueden esperar la acción del poder central para buscar lo beneficios que persiguen, en concordancia con las aportaciones antes señaladas de Ohmae, Laïdi \& Kennedy.

La formalización del proyecto, se encontró reflejada en la visión gubernamental al otorgarle un importante espacio en la redacción del Plan Estatal de Desarrollo, que representa el primer indicio hacia la consolidación de este ideal integracionista una vez analizadas tanto las ventajas que supone la vecindad con los estados circundantes, como los procesos de complementación mundial en diversas subregiones del globo.

El Plan estatal (2003-2009) contempló quince estrategias que hemos resumido en las siguientes líneas generales de acción. En primer lugar, con la finalidad de mantener una administración eficiente por parte del estado, se planteó la necesidad de crear una Coordinación Ejecutiva cuyas funciones fueran la organización, planificación e instrumentación de los mecanismos institucionales para implementar el proyecto de integración subregional. Derivado de lo anterior, se acordó la formación de un Consejo "que permitiría, en un escenario de corto y mediano plazos, construir los mecanismos, los acuerdos, los planes, los programas y las estrategias en torno al proyecto de vinculación regional" (Gobierno del Estado de Nuevo León, 2003), por lo que dentro de éste se proyectó la inclusión de los gobernadores de los tres estados mexicanos participantes. 
En segundo lugar, se creó el Convenio para el Desarrollo Integral Regional del Noreste de México, alianza que había de ser firmada por los gobernadores de las entidades que se incluyen en el proyecto, la cual generaría la creación de un cuerpo de representantes de manera permanente dentro de los estados implicados. Para ello se requería de la institucionalización de los compromisos, a través de acciones tales como el desarrollo de infraestructura carretera, la promoción de inversiones conjuntas de empresarios en dicha subregión, el diseño y la instrumentación de políticas públicas regionales de largo plazo en asuntos económicos, ecológicos y sociales así como la implementación de actividades conjuntas en materia educativa, cultural, científica, deportiva y de solidaridad social en coordinación con los gobiernos de Coahuila, Tamaulipas y Texas (Gobierno del Estado de Nuevo León, 2003). Con lo que se esperaba poder coadyuvar al aumento de vínculos regionales en beneficio de la población que habita en este territorio y, al mismo tiempo, contribuir al fortalecimiento de los niveles de aplicabilidad de este proyecto bajo la óptica de hacer frente a los procesos mundiales de integración en diversas partes del mundo.

Una vez que este proyecto se constituyó como una prioridad del gobierno del Lic. José Natividad González Parás, el primero paso para su realización consistió en la formación de una Coordinación especial encargada de éste y la firma del denominadoAcuerdo Regional Asociado. Con fecha del viernes 5 de Marzo del año 2004, fue publicado en el Periódico Oficial del estado de Nuevo León el acuerdo que crea el Programa para Integración del Desarrollo Regional del Noreste y su Vinculación con Texas. En él se establecían las bases legales por medio de las cuales al gobernador del estado se le otorgaban las facultades necesarias para desarrollar e implementar este proyecto y todo lo relacionado a él en términos institucionales. No obstante, ya desde el año 2003 había sido promulgada y publicada una nueva ley de la administración pública en donde se establecía que:

El gobernador del Estado podrá contar con unidades administrativas, cualquiera que sea su denominación u organización, para coordinar, planear, administrar o ejecutar programas especiales o prioritarios a cargo de la Administración Pública, como lo es sin 
duda el proyecto para impulsar, a través de la integración regional de los Estados del Noreste de México y su vinculación con Texas (Gobierno del Estado de Nuevo León, Diario oficial, 2004).

El resultado final lo constituyó la publicación de un acuerdo que estableció las bases por medio de las cuales este proyecto estratégico debía funcionar en el marco de cooperación con las entidades vecinas a Nuevo León, es decir, Tamaulipas, Coahuila y Texas. Dicho convenio constaba de trece artículos, teniendo como misión diseñar, impulsar y coordinar estrategias y acciones tendientes a desarrollar un proceso de integración regional y de cooperación en asuntos económicos, sociales, de medioambiente, culturales, entre otros, del Estado de Nuevo León con los Estados del Noreste de la República Mexicana, Tamaulipas, Coahuila y Chihuahua, y su vinculación con el Estado de Texas, en los Estados Unidos de América.

Como parte de este acuerdo, y de las estrategias y acciones establecidas en su misión, se plantearon seis objetivos específicos: 1. Planear, formular e instrumentar mecanismos de coordinación institucional en materia económica, industrial, comercial, agrícola, energética, de educación, de ciencia y tecnología, desarrollo urbano, ecología, entre otros. 2. Fomentar la creación de polos de desarrollo. 3. Promover la participación de los sectores públicos, social y privado. 4. Fomentar la inversión en proyectos de investigación y desarrollo tecnológico. 5. Impulsar el establecimiento de una nueva cultura de intercambio económico, comercial, social, académico, cultural, de turismo y de cuidado del medioambiente. 6. Los demás que establezca el Gobernador del Estado y aquellos que en atención a su objeto o naturaleza correspondan.

Un punto importante en el desarrollo e implementación de este acuerdo fue la formación de una unidad administrativa que contara con la capacidad de coordinar todas las líneas de acción. Esta nueva instancia llevó por nombre Coordinación del Programa para Integración del Desarrollo Regional del Norestey su Vinculación con Texas, que representaba la instancia principal encargada de dar seguimiento a su ejecución. 
Si bien el Estado de Nuevo León no cuenta, ni contaba en esa administración con una oficina destinada específicamente a llevar a cabo el ejercicio de la actividad paradiplomática, se crearon algunos organismos encargados de ejecutar y vigilar las cuestiones en torno a sus relaciones con el exterior, tal es el caso de la Oficina ejecutiva de la gubernatura, en su Unidad de Asuntos Internacionales; el Programa para la Integración del Desarrollo Regional del Noreste y su vinculación con Texas, también conocido como INVITE; la Corporación para el Desarrollo de la zona fronteriza de Nuevo León o CODEFRONT, por sus siglas; la Dirección de Relaciones Federales, Consulares y de Atención al Migrante, oficina que se encuentra dentro de la Secretaría General de Gobierno, y la Secretaría de Desarrollo Económico.

\section{El Programa para la Integración y Desarrollo Regional del Noreste y su vinculación con Texas}

En la conformación de un Estado-región subyacen diversos elementos que, por su importancia estratégica, deben ser considerados fundamentales en la construcción de dicho proceso. Entre esos factores destacan aspectos como las transacciones comerciales, los flujos de personas, las relaciones empresariales, la identificación con el área geográfica, entre otros; sin embargo, se requiere de la institucionalización de todas estas actividades a fin de que estos se lleven a cabo de manera más efectiva. En este sentido, el Estado de Nuevo León se caracterizó por ser pionero en formular e impulsar su propia perspectiva del área geográfica en el que se encuentra inmerso; prueba de ello lo representa la instauración de la primera oficina gubernamental encargada de administrar un proyecto de integración con sus estados vecinos.

La Coordinación del Programa para Integración del Desarrollo Regional del Noreste y su vinculación con Texas (Programa INVITE) es un claro ejemplo de la forma en que el estado asumió el liderazgo en la región, así como el compromiso de crear un marco institucional que diera certidumbre al proyecto. Esta unidad, dependiente del gobierno estatal, se propuso llegar a ser una "promotora del progreso, el desarrollo social, la innovación tecnológica y el crecimiento económico, capaz de diseñar, 
impulsar y coordinar estrategias y acciones tendientes a desarrollar un proceso de integración regional y de cooperación" (Gobierno del estado de Nuevo León, 2004, [en línea]), a través del establecimiento de políticas públicas y acciones conjuntas para beneficiar y fortalecer el desarrollo de la Región Noreste de México y Texas con una visión integral. Dicho propósito se encontraba plasmado dentro de su misión: "impulsar por medio de la integración regional y vinculación con Texas, la segunda etapa del Tratado de Libre Comercio de América del Norte" (Gobierno del estado de Nuevo León, [en línea])". De esta manera INVITE se convirtió en el programa estratégico de mayor injerencia en el proceso de integración regional y de cooperación internacional en asuntos económicos, sociales, políticos y de medioambiente del Estado de Nuevo León, con los estados del noreste de la República Mexicana y con el Estado de Texas.

A través del Programa INVITE se intentó impulsar un proyecto de largo plazo que coincidiera con las grandes transformaciones mundiales, ya que buscaba un mayor acercamiento entre los tres estados fronterizos del noreste mexicano, por lo que "INVITE fue una dependencia auxiliar del gobierno del estado que, como única unidad administrativa ex profeso para coordinar y monitorear el proceso de integración regional, hace de Nuevo León un eje de liderazgo natural desde donde se estarían presentando proyectos en varias materias" (Gobierno del estado de Nuevo León, 2007, [en línea]). Para el logro de sus objetivos, dicha coordinación estuvo organizada a través de una coordinación ejecutiva de la que se derivaban tres direcciones: La de negociaciones interinstitucionales e intergubernamentales, la de los proyectos estratégicos y especiales, y la de Integración económica regional (Gobierno del estado de Nuevo León, 2007).

De manera general, podemos señalar que el Programa INVITE buscó alcanzar diversos objetivos entre los que destacan el desarrollo de políticas regionales de carácter económico, ecológico, científico y social; el fomento de la participación de diversos sectores nacionales e internacionales en la región; la promoción de investigación e inversión en la región, y la promoción de una cultura de integración e intercambio regional (Gobierno del estado de Nuevo León, 2007), 
para lo cual creó una serie de mecanismos e instrumentos entre los que destacan: el Consejo de Gobernadores (considerado como la "instancia superior que define las políticas de Integración Regional y la creación de Comisiones"), un Secretariado técnico, y una serie de Comisiones Regionales que se dividían en temas para la cooperación en materia de agricultura, ciencia y tecnología, energía, medio ambiente, turismo, seguridad, etc. (Gobierno del estado de Nuevo León, 2007).

Más allá de discursos simbólicos en donde se proclame la intención de desarrollar un área en común, el gobierno del estado de Nuevo León ejerció un verdadero papel de promotor de estrategias que condujeran a la consolidación de los acuerdos, ampliando su visión más allá de las fronteras estatales. Así, Nuevo León fue el primero en desarrollar e implementar diversas acciones y aterrizarlas a proyectos concretos, tomando como referencia un contexto de globalización y de una intensa competencia entre regiones económicas a escala mundial [en donde] las políticas públicas y las acciones conjuntas para fortalecer el desarrollo regional cobraban gran relevancia (Gobierno del Estado de Nuevo León, [en Línea]). De esta manera, el establecimiento de diversas comisiones regionales por parte de Nuevo León representó la primera acción concreta para trabajar de manera específica sobre temas que afectaban de manera general la región noreste de México. Entre estas comisiones o mesas de trabajo destacaron aquellas cuya tarea se enfoca en la concertación política, en la integración económica-social, integración educativa, cultural, científica y tecnológica y aquella encargada de la concertación legislativa con el objetivo de "crear un marco jurídico que confiera certidumbre a las inversiones en la región (Gobierno del Estado de Nuevo León, [en Línea]).

\section{El Acuerdo para un Progreso Regional Asociado}

En aras de seguir avanzando en la construcción de una zona común de cooperación en la región noreste, los gobernadores de Nuevo León, Coahuila, Tamaulipas y Texas firmaron en Monterrey el Acuerdo para un Progreso Regional Asociado, que ofrecía el marco para la colaboración a nivel estatal en políticas y proyectos que impactaran 
en el futuro económico compartido de estas entidades, el cual vino a ser la continuación del Acuerdo para el Desarrollo Sustentable en el Noreste.

Con la firma del denominado Acuerdo para un Progreso Regional Asociado, con fecha del 22 de junio de 2004, se puso de manifiesto el interés de las 4 entidades por profundizar e incrementar vínculos entre ellas para el beneficio de sus propios habitantes y de la subregión misma. Conjuntamente expresaron que tenían interés en unir esfuerzos para establecer las bases a través de las cuales, en el ámbito de sus respectivas competencias, se pudiese llevar a cabo programas de cooperación técnica y vinculación de los estados en materia de desarrollo económico, medioambiente, flora, fauna, educación, cultura, seguridad, enlaces fronterizos, turismo e infraestructura de comunicaciones y transportes, así como establecer políticas y llevar acciones conjuntas que contribuyesen a racionalizar y fortalecer el desarrollo de la Región Noreste de México y Texas con visión integral.

Destaca de este Acuerdo la instauración de un Consejo de Gobernadores con la facultad de realizar sesiones tanto ordinarias como extraordinarias, con el propósito de analizar y diseñar las acciones que se consideraran convenientes de manera conjunta para la cristalización del proyecto regional. Por otro lado, estos mismos estados decidieron, a fin de enfrentar de mejor manera la competencia internacional, establecer una representación del otro lado del Río Bravo, en la ciudad de Houston. La oficina en cuestión llevó por nombre NEMEX-TEX, la cual buscaba institucionalizar la estrategia de Nuevo León, Coahuila y Tamaulipas para vincularse con el estado de Texas.

Entre sus principales objetivos se destacaban aquellos encaminados a reforzar la relación entre los estados, con más carreteras, autopistas, puentes fronterizos, tramos ferroviarios, infraestructura de telecomunicaciones y puertos marítimos. Además, participaba en la activa promoción de los objetivos, programas y proyectos que llevasen a la integración económica del noreste de México con Texas, a través de la identificación, desarrollo y promoción de proyectos que integraran y estimularan la competitividad regional. 
Esta oficina de representación, promovía y consolidaba las relaciones de trabajo entre los agentes económicos, académicos, tecnológicos e institucionales que pudiesen estimular proyectos de inversión, de desarrollo y transferencia de tecnología, así como de la integración de infraestructura moderna. De esta manera, la instauración de esta oficina representaba un paso más en la búsqueda de aumentar la cooperación y los medios adecuados para la efectiva implementación y avance del proyecto subregional (NEMEX-TEX, 2007).

Con base en la Ley Orgánica de la Administración Pública del estado de Nuevo León, acorde a la Constitución mexicana y la Ley Orgánica de la Administración Pública Federal, ninguna dependencia de gobierno estatal contaba con atribuciones o facultades para ejercer política exterior; no obstante, la actividad paradiplomática del estado se hallaba articulada bajo todo un esquema institucional y burocrático administrativo que garantizaba su ejecución, seguimiento y en principio, continuidad.

\section{Rubros de actividad paradiplomática de Nuevo León}

Desde el punto de vista de las actividades económicas desplegadas por las entidades de la federación, más allá de las fronteras nacionales, hemos de recordar a autores como López \& Schiavon (2005), quienes sostienen que en la medida en que una entidad federativa posea un mayor nivel de ingresos, medido por medio de su Producto Interno Bruto (PIB), esto supone que tendrá mayores recursos económicos para invertirlos en políticas públicas, entre ellas la participación internacional. En este sentido hemos de recordar que la economía de Nuevo León ocupaba el segundo lugar a nivel nacional, tan solo por debajo del Distrito Federal, según información proporcionada por el INEGI en datos referentes al año 2004. Además, si consideramos su posición geográfica, la cual le otorga cercanía con Estados Unidos, el estado guarda una activa relación con el exterior. Además, la ciudad de Monterrey fue considerada en el 2008, según la revista América Economía, como la primera ciudad para hacer negocios y la tercera en Latinoamérica, después de San Paulo, en Brasil, y Santiago de Chile (Secretaría de Desarrollo Económico del Estado de Nuevo León, 
2007, en línea), ${ }^{6}$ todo lo cual incidió de manera directa en la agenda económica internacional del gobierno neoleonés de aquel entonces.

Entre los acuerdos contraídos por el estado de Nuevo León, en aquella administración, destaca el de cooperación económica con el Estado de California firmado el mes de noviembre de 2006 entre el Gobernador Arnold A. Schwarzenegger y su homólogo José Natividad González Parás. Con éste se buscaba explorar áreas de negocio entre ambas entidades, así como fomentar el turismo y el intercambio científico y tecnológico.

Otra característica de la vertiente económica de la actividad paradiplomática del estado de Nuevo León fueron las giras que realizó el Ejecutivo con el principal objetivo de captar inversión extranjera. A pesar de la creciente relación que se tenía con los Estados Unidos de América debido al TLCAN, las giras se orientaron a países asiáticos como China y Japón. En este sentido, es pertinente resaltar también la participación del Gobernador en el Foro Económico Mundial celebrado anualmente en Davos, Suiza (Gobierno del estado de Nuevo León, 2004).

Además de las labores del Ejecutivo, recordemos que la Secretaría de Desarrollo Económico (SEDEC) es la dependencia encargada de potenciar las relaciones económicas del Estado, ya que es la encargada de desplegar una intensa actividad internacional con miras a atraer inversión extranjera y generar las oportunidades y condiciones propicias para impulsar la actividad exportadora de la.

\section{La agenda política internacional de Nuevo León}

Si bien son las prioridades económicas y comerciales las que han dominado la agenda internacional de Nuevo León, la esfera política

\footnotetext{
6 En el periodo de González Parás, Monterrey fue varios años consecutivos colocada, por la revista América economía dentro de las cinco primeros ciudades de América latina para hacer negocios. Este ranking se verá seriamente afectado por la inseguridad que estalla a partir de 2010.
} 
también ha ido adquiriendo cada vez más un lugar destacado en la actividad paradiplomática de la entidad, lo cual se ha materializado en la firma de una serie de acuerdos internacionales de amistad y cooperación, orientados a promover acciones en diversas áreas, entre las que destacan la cultura, la educación, la inversión económica, el turismo, entre otras. En la administración estatal 2003-2009, esto se materializó en los siguientes instrumentos:

Memorando de Entendimiento entre el estado de Colorado y Nuevo León, firmado en el mes de octubre de 2006 en la entidad. Dicho acuerdo estaba encaminado a "fortalecer el vínculo económico, social y cultural entre ambas entidades" (Gobierno del Estado de Nuevo León, [en Línea]).

Memorando de Entendimiento entre el estado de California y Nuevo León. Suscrito en el mes de noviembre de 2006 en territorio neoleonés, a través del cual se alienta la cooperación comercial y educativa entre ambos estados.

Memorando de Entendimiento entre la provincia de Manitoba y Nuevo León. Firmado en junio de 2006 en Canadá, “con el fin de implementar acciones en materia de intercambio de inversiones y fortalecer las relaciones comerciales con las que ya se cuenta" (Gobierno del Estado de Nuevo León, [en Línea]).

Convenio entre el estado de Maryland y Nuevo León. Firmado en abril de 2005 en territorio estadounidense, cuyo objetivo era hacer intercambios en investigaciones científicas y de "experiencias en desarrollo económico y proyectos de reestructura urbana" (Gobierno del Estado de Nuevo León, [en Línea]).

Memorando de Entendimiento entre la provincia de Quebec y Nuevo León: Contraído en mayo de 2006 durante la gira del gobernador del Estado por Canadá, dicho acuerdo buscaba "facilitar el desarrollo de oportunidades en materia económica, cultural, de cooperación institucional y de administración pública, así como la 
participación de Quebec en el Fórum Universal de las Culturas" (Gobierno del Estado de Nuevo León, [en Línea]).

Parte importante de la actividad internacional del estado se manifiesta en el número de giras que el Ejecutivo llevó a cabo a lo largo de los años de su administración. Destacan sus repetidas visitas a Estados Unidos, aunque paísese como Canadá y otros de Asia y Europa también estuvieron en su agenda. El país que más visitó el Gobernador González Parás en su administración fue Estados Unidos. Sus giras tuvieron como destino las ciudades de Austin, Houston, San Antonio, Washington, Santa Fe, entre otras. Su agenda en la Unión Americana incluyó reuniones de gobernadores fronterizos, proyectos del NadBank, así como iniciativas en temas de infraestructura urbana, equipamiento y diversas áreas vinculadas con la competitividad y el desarrollo regional (Gobierno del Estado de Nuevo León, [en Línea]). Además, el titular del ejecutivo participó como panelista en Conferencias, encuentros y como invitado en distintos eventos, entre los que destaca su asistencia como invitado Especial a la Celebración del 5 de Mayo de 2005 con el Presidente George W. Bush, en la Casa Blanca (Gobierno del Estado de Nuevo León, 2006).

En Canadá, el gobernador de Nuevo León realizó giras de trabajo donde visitó las ciudades de Quebec y Gimli, destacando de sus actividades la firma junto con el Primer Ministro Charest, del Memorándum de Entendimiento ante el Gobierno de Quebec y el Gobierno de Nuevo León, el cual buscaba facilitar el desarrollo de oportunidades en materia económica, cultural, de cooperación institucional y de administración pública, así como la participación de Quebec en el Fórum Universal de las Culturas (Gobierno del Estado de Nuevo León, 2006).

A partir del 2004 sus giras en Europa se enfocaron en España para gestionar distintos proyectos entre los que destacó la obtención de la sede del Forum Universal de las Culturas 2007. Además de atraer inversión extranjera, formalizar acuerdos para fortalecer el proyecto de la Ciudad Internacional del Conocimiento, realizó encuentros con miembros del Gabinete del Gobierno Español y con la comunidad 
académica e intelectual de Madrid (Gobierno del Estado de Nuevo León, [en Línea]).

Adicionalmente, sus visitas por Europa incluyeron encuentros con el Secretario General de la Organización de las Naciones Unidas para la Educación, Ciencia y Cultura (UNESCO, por sus iniciales en inglés), Koichirō Matsuura, con el fin de preparar los trabajos preeliminares para la realización del Fórum en Monterrey y para discutir los apoyos por parte del organismo (Gobierno del Estado de Nuevo León, [en Línea]). Además, en París se reunió con empresarios franceses miembros de la Asociación de Cámaras Industriales de Francia que había "demostrado un interés en el Estado como posible destino de su inversión” (Gobierno del Estado de Nuevo León, [en Línea]) en los sectores automotriz, aeroespacial y de software. En este mismo país visitó Toulouse, en donde mantuvo encuentros con algunas de las empresas más, importantes de la industria Aeroespacial, entre ellas de Airbus, debido al creciente interés de trasladar plantas al Estado de Nuevo León, ya que se ha ido ampliando un cluster en formación de industria Aeroespacial. Visitó en Marsella para ver una experiencia concreta de formación de una zona del conocimiento, misma que se ha realizado con la participación de instituciones académicas gubernamentales y empresariales en esa región (Gobierno del Estado de Nuevo León, [en Línea]).

Siguiendo la agenda europea, el ejecutivo estatal visitó Italia dentro del marco de la Feria de Milán en la que se reunió con funcionarios y empresarios italianos con el objetivo de analizar la viabilidad de desarrollar ferias temáticas e institucionales en Monterrey y sus instalaciones como el Parque Fundidora (Gobierno del Estado de Nuevo León, 2005a).

Siguiendo con las visitas oficiales por Europa, Natividad González Parás realizó tres viajes a Davos como invitado para formar parte del Foro Internacional de Davos como miembro asociado. Este evento reúne a los líderes empresariales más importantes del mundo y a Jefes de Estado. En estos viajes el gobernador sostuvo reuniones con algunos de los líderes empresariales más importantes de mundo, con 
el fin de lograr atraer inversión al Estado (Sala de Prensa, Gobierno del Estado de Nuevo León, 2005b).

La agenda internacional también incluyó la región de Asia, en la que visitó Japón, China e India. La orientación a esta región fue principalmente de carácter económica pero también con tintes culturales y educativos" (Gobierno del Estado de Nuevo León, 2005). Con estos viajes se buscó "promocionar al Estado como plataforma de producción y comercio para el mercado de China, así como incrementar el intercambio comercial que se tiene con Japón" (Gobierno del Estado de Nuevo León, 2005). En esta visita, el jefe del ejecutivo estatal estuvo acompañado por los rectores de las dos Universidades más importantes de la entidad, El Tecnológico de Monterrey (ITESM) y la Universidad Autónoma de Nuevo León (UANL), y por empresarios. El viaje se realizó atendiendo la invitación de la Organización de la Naciones Unidas y del alcalde de Shangai, Han Zheng para participar en el sexto Foro de Informatización de Ciudades en la Región AsiaPacifico. En este viaje se llevaron a cabo diálogos para promover intercambios en materia educativa y cultural (Sala de Prensa, Gobierno del Estado de Nuevo León, 2006) y en Japón mantuvo reuniones con miembros de la Liga Parlamentaria México-Japón, encabezados por el Presidente del Comité de Relaciones Exteriores de la Cámara Baja, Taimei Yamaguchi. González Parás también participó en el Seminario de Promoción a la Inversión en el marco del Acuerdo de la Asociación Económica entre México y Japón, en donde expuso las ventajas comparativas que ofrece Nuevo León para la inversión extranjera. Por otra parte, durante el año 2008se entrevistó con los altos ejecutivos de WIPRO y Quintegra Solutions en la ciudad de Bangalore, India, con el propósito es establecer una relación estratégica en los sectores de Tecnologías de la Información y Biotecnología.

Si bien las giras arriba referidas no son todas las que se llevaron a cabo, si son un claro ejemplo de la intensa actividad internacional que implementó el gobierno de Nuevo León como parte de su estrategia de posicionar a la entidad en el escenario internacional en los ámbitos políticos, económicos, artísticos y culturales, al mismo tiempo que se impulsaba la conformación del espacio regional noreste del país. 
Cabe destacar que la actividad internacional del Estado no se circunscribió únicamente a giras y viajes del ejecutivo estatal al extranjero; también el estado fue sede y anfitrión de un número importante de visitas, las cuales contaron con una agenda amplia; pero, destacan aquellas que se enfocaron principalmente a atender asuntos relacionados con el sector empresarial. El papel del gobierno del Estado ha sido el de vincular a los distintos grupos empresariales de Nuevo León con los empresarios del extranjero. Sin embargo con motivo del Forum Internacional de las Culturas Monterrey 2007 las visitas de embajadores y políticos se vieron incrementadas.

Nuevo León recibió entre 2004 y 2009 la visita de funcionarios y dignatarios del extranjero, entre ellos los embajadores y representantes del Reino Unido, Estados Unidos, Chile, España, Francia, Tailandia, Vietnam, Italia, Hungría, Japón, Israel, Turquía, Corea del Sur, Taiwán y Suiza. También se atendió a la gobernadora de Arizona y los gobernadores de Idaho y Texas, así como la visita de los Príncipes de Asturias Felipe de Borbón y Leticia Ortiz y el Alcalde de Barcelona Joan Clos (Gobierno de Nuevo León, 2004). Por ejemplo, durante el año 2005 se realizaron 39 visitas de funcionarios y dignatarios extranjeros al estado. Además, se atendió a funcionarios de naciones como Costa Rica, Irlanda, Estados Unidos, Polonia, Italia, Suiza, República Checa, Corea del Sur, Israel, Canadá, Francia, Japón, Australia, Taiwán, Alemania y Cuba. Los temas de la agenda incluyen negocios, educación y cultura, toda vez que Nuevo León despierta cada día mayor interés en el mundo.

Además de los encuentros con funcionarios de alto nivel, jefes de estado e importantes empresarios, el gobierno del estado de Nuevo León puso énfasis en establecer relaciones con organismos financieros, tales como el Banco Mundial. Recordemos que en abril del 2006 el gobernador se reunió con Paul Wolfowitz, en ese entonces presidente del organismo. Durante su encuentro hablaron "sobre algunos de los proyectos de la actual administración como son la concreción de la Ciudad Internacional del Conocimiento, el esquema de desarrollo regional asociado entre el noreste de México y Texas y proyectos estratégicos que propiciarán transformaciones en el mediano y largo 
plazos"(Gobierno de Nuevo León, 2006c).También se aprovechó la oportunidad para analizar la viabilidad de que el Banco Mundial pueda financiar proyectos de inversión en materia tecnológica en el Estado.

De forma general podemos afirmar que el propósito de toda la actividad paradiplomática del estado de Nuevo León entre el 2004 y el 2009 fue la de mejorar su imagen hacia el exterior y lograr capturar un mayor interés por parte de la comunidad internacional. Los organismos y dependencias del estado, así como los planes de gobierno que hemos mencionado fueron creados para lograr que ese objetivo se cumpliera. En suma, los esfuerzos del Estado se encontraban encaminados hacia tres principales áreas de interés: (1) Promoción de Nuevo León para atraer inversión extranjera. (2) Consolidación del proyecto de Monterrey como Ciudad del Conocimiento y (3) Promoción del Fórum Internacional de las Culturas.

Otro tipo de actividad que el gobierno de Nuevo León encabezó con el propósito de promoverse en el exterior fue llevar a cabo festivales culturales, principalmente en ciudades estadounidenses, como fue el caso de la Semana Cultural de Nuevo León que se celebró en la ciudad de San Antonio, Texas en Marzo del 2006. Un evento similar fue conducido en Washington dos meses después (Gobierno de Nuevo León, 2006a).

Cabe destacar que si bien las instancias públicas, encabezadas por los gobiernos estatales son los actores en los que se centra la agenda paradiplomática, no podemos dejar de mencionar la influencia y el peso que ejerce el sector privado, particularmente el empresarial, ya que ellos han sido parte esencial del desarrollo económico de la región. Enfocarnos únicamente al plano gubernamental es ignorar el desempeño histórico del sector empresarial del noreste, ya que en palabras de Ohmae éstos son parte de la fuente de prosperidad de una región.

Los grandes consorcios regiomontanos como Alfa, Cemex, Cydsa, FEMSA, Imsa, Proesa y Vitro representan un alto nivel de globalización en sus actividades productivas. Un importante indicador lo constituye 
el elevado número de alianzas estratégicas con empresas extrajeras. En su conjunto estas empresas son responsables de la participación en México de por lo menos 21 diferentes socios norteamericanos y 16 europeos. En tanto que las empresas mexicanas también han invertido en el exterior, hasta llegar a tener participación en por lo menos 14 diferentes empresas en Estados Unidos y 16 en América Latina. Asimismo, la producción para la exportación sigue ocupando un papel esencial en la estrategia de estos consorcios, pero la importancia de sus experiencias de producción internacional se desarrolla rápidamente, revelando un intenso proceso de transición. De acuerdo a Pozas, lo que inició como una estrategia defensiva ante la apertura y la inminente llegada al país de sus competidores extranjeros, se convirtió después en punta de lanza de su estrategia de expansión y en la principal forma de acceso a los mercados de sus socios y al capital internacional.

Es importante recalcar el hecho de que el éxito de la elite empresarial de Monterrey está ligado al establecimiento de alianzas estratégicas con empresas extranjeras, y que en general tienen en común los conglomerados nuevoleoneses, además de su gran tamaño y su amplia participación en el mercado nacional, sus experiencias previas de alianzas y convenios estratégicos con socios extranjeros. Por lo tanto es claro que de manera indirecta, existe la intervención de actores externos en el proyecto de integración al tener vínculos los grandes conglomerados con empresas extranjeras.

Sin duda alguna el Estado de Nuevo León realizó durante la administración 2003-2009 una serie de planes, acciones y estrategias, que lo fueron configurando como el actor principal dentro del proyecto de integración subregional, proceso en el cual destacaron de manera especial los empresarios regiomontanos como motores del desarrollo económico, tanto por la larga historia y tradición que los caracteriza, como por su gran potencial productivo con empresas que se han posicionado a nivel mundial, como es el caso de CEMEX, por solo mencionar el ejemplo más conocido. De igual manera, el papel del liderazgo de Natividad González en el estado puede calificarse como emprendedora, ya que ha sabido mover los hilos necesarios para que 
el proyecto de integración pudiese avanzar y concretarse como una realidad en un futuro cercano, a través de los medios e instancias gubernamentales que, se esperaba, dieran fluidez al ejercicio, cada vez más intenso de su paradiplomacia.

\section{Conclusiones}

El concepto de subregión hace referencia a un proceso que se fue desarrollando cada vez con más fuerza en la frontera noreste de México y Texas, pues con ésta se intentaba responder a las necesidades comerciales, económicas, y sociales de la región, dejando a un lado la geografía comúnmente conocida, anclada en las nociones clásicas del estado y la soberanía, para dar paso a un nuevo trazo de los límites del Estado-nación. En este escenario, Nuevo León había tomado las riendas del proyecto a partir de los distintos acuerdos, conferencias $\mathrm{y}$ eventos internacionales que fueron consolidando su imagen hacia el exterior y fortaleciendo su liderazgo, dando paso a la construcción de una figura que trascendía las fronteras nacionales.

El gobierno de Natividad González Parás, en su momento, se enfocó en diseñar estrategias puntuales para aumentar los vínculos de cooperación, con la finalidad de encontrar soluciones a los problemas que aquejaban, y lo siguen haciendo, a esta zona de manera conjunta. Sin embargo, la continuidad de este proyecto se vio fuertemente condicionada por la voluntad y apertura que el gobernador que lo relevó mostró.

La paradiplomacia de Nuevo León logró consolidarse en la administración de Natividad González, lo cual no solo se expresó en los proyectos económicos y comerciales puestos en marcha, sino en el amplio despliegue de iniciativas en diversas áreas, entre las que destacó la cultural, cuya mayor expresión la ilustró el Forum de la Culturas Monterrey 2007. Asimismo, el Gobierno del Estado promovió acuerdos internacionales, estableció representación en el extranjero y aumentó el número de convenios de hermanamiento de ciudades. Sin duda, el Ejecutivo en conjunto con los departamentos y áreas ad hoc, como la de Asuntos Internacionales, dio soporte a una actividad 
paradiplomática en la búsqueda de incentivos para aumentar la capacidad de negociación del Estado con el exterior y su desarrollo interno en lo económico, político, social, científico-tecnológico y cultural.

La paradiplomacia llevada a cabo por Nuevo León reforzó uno de los principios fundamentales de la globalización, que es hacer posible la cooperación internacional en pro del desarrollo regional, estatal y municipal. La conjunción de esfuerzos entre el sector público y privado, y la sociedad en general, a nivel nacional e internacional, es una dinámica que Nuevo León impulsó para estar a la altura de la competencia internacional. No obstante, aún debían enfrentarse retos importantes entre los que destacaban: las relaciones con el gobierno federal, el combate a la delincuencia y el crimen organizado, la inseguridad, y los problemas derivados de la enorme brecha que separa a ricos y pobres, no solo del Estado, sino como reflejo de la realidad nacional.

Un proyecto de integración subregional como el que se puso en marcha en la frontera noreste de México pondría a prueba la madurez del sistema político mexicano y el ejercicio del federalismo real, al mismo tiempo que debería superar los vaivenes derivados de los cambios gubernamentales y los enfrentamientos partidistas a fin de evitar que este tipo de iniciativas queden más como planes gubernamentales y no como reflejo efectivo de políticas de Estado con visión de largo plazo.

El relevo en el ejecutivo estatal acaecido en el 2009 que llevó a la gubernatura a Rodrigo Medina de la Cruz para el sexenio 20092015 puso de manifiesto que la actividad paradiplomática, si bien teóricamente supone el establecimiento de una serie de instancias burocrático-administrativas así como un orden normativo que dé certidumbre jurídica y continuidad a las iniciativas implementadas, el caso de Nuevo León es claro ejemplo de que el modelo no siempre tiene viabilidad en la realidad.

Desde el arribo de Rodrigo Medina a la gubernatura del Estado y los subsecuentes 6 años de su administración ha sido clara la pérdida de 
presencia internacional de la entidad. Aunado a ello, la desaparición del programa INVITE trajo aparejado la suspensión, al menos de facto, de los proyectos en torno a la consolidación de la zona noreste del país con Texas. Asimismo, la desaparición de distintas instancias encargadas de la promoción y seguimiento de la agenda internacional son clara evidencia de la perdida de interés en la paradiplomacia como mecanismo de proyección de la entidad y de su subsecuente atracción de recursos del extranjero.

Ciertamente la actividad económica siguió arrojando números importantes, gracias a la labor realizada desde la Secretaría de Desarrollo Económico. Sin embargo, la paradiplomacia debiera ir más allá de las cuestiones meramente económicas, comerciales y de inversión.

Sin lugar a dudas, más allá de las premisas teóricas del institucionalismo y de los modelos de procesos organizacionales, y de políticas burocráticas, podemos afirmar que el fuerte impulso de la paradiplomacia llevado a cabo en la administración de Natividad González Parás respondió más a su propia personalidad, a su liderazgo y a lo que los teóricos definen como la personalidad de los líderes. Resulta evidente que, a diferencia de la diplomacia federal, institucionalizada y trans-administrativa, la paradiplomacia está ligada a la personalidad del gobierno en turno y puede pasar de una administración a otra, de ser una actividad intensa, prioritaria, plasmada en un Plan Estatal de Desarrollo a una de muy bajo perfil tal y como lo ponen en evidencia las 2 últimas administraciones en el Estado de Nuevo León.

\section{Referencias}

Allison, Graham, T. (1988). La esencia de la decisión: Análisis explicativo de la crisis de los misiles en Cuba. Buenos Aires: Grupo Editor Latinoamericano.

Coalición de la Cuenca Río Bravo/Río Grande. (2006). Desarrollo Sostenible para la Cuenca del Río Grande/Río Bravo. Recuperado de: http://www. rioweb.org/

Cusimano, M. K. (1999). Más allá de la soberanía. El surgimiento de los problemas transoberanos. Boston: Bedford/St. Martins. 
Farías Campero, C. (2005). Nuevo León de cara al siglo XXI. Monterrey: Gobierno del Estado de Nuevo León-Fondo Editorial de Nuevo León.

Gobierno de Nuevo León. (2004). Plan Estatal de Desarrollo 2004-2009. México: Gobierno del Estado.

Gobierno del Estado de Nuevo León. (2004a). Constitución Política del Estado de Nuevo León. Recuperado de: http://www.ordenjuridico.gob.mx/ Estatal/NUEVO\%20LEON/Constitucion/Constituci $\% \mathrm{~F} 3 \mathrm{n} \% 20$ Pol $\%$ EDtica $\% 20$ del $\% 20$ Estado $\% 20 L i b r e \% 20 y \% 20$ Soberano $\% 20$ de $\% 20$ Nuevo $\% 20 L e \%$ F3n.pdf

Gobierno del Estado de Nuevo León. (2004b). El Gobernador del estado y sus dependencias. Libro Segundo. En Gobierno del Estado de Nuevo León, Manual de Organización Generaly de Servicios. Recuperado de: http://www2.nl.gob.mx/pics/pages/organigrama_gral_gob_ edo_base/LibroII.pdf

Gobierno del Estado de Nuevo León. (2004c). Entrevista concedida a los medios de comunicación por el C. Gobernador del Estado de Nuevo León, Lic. José Natividad González Parás. Recuperado de: http://www.nl.gob.mx/?A rticle $=20819 \&$ ArtOrder $=$ ReadArt $\& \mathrm{P}=$ leerarticulo $\&$ Page $=1$

Gobierno del Estado de Nuevo León. (2004). Plan Estatal de Desarrollo 20042009. Recuperado de: http://www.nl.gob.mx/?P=plan_desarrollo

Gobierno del Estado de Nuevo León. (2005). Segundo Informe de Gobierno de Nuevo León 2005. Recuperado de: http://www.nl.gob. $\mathrm{mx} /$ ?P=segundo_informe

Gobierno del Estado de Nuevo León, (2005a). Se reúne Gobernador de N.L. con empresarios y organizadores de la Feria de Milán. Recuperado de: http:/ / www.nl.gob.mx/?Article=23405\&ArtOrder=ReadArt\&P=leerarticu lo\&Page $=1$

Gobierno del Estado de Nuevo León. (2005b). Participará el Gobernador José Natividad González Parás en el Foro Económico en Davos, Suiza. Recuperado de: http://gobierno.nl.gob.mx/EspecialesPortada/ Enero2005/22Enero/22-01-05

Gobierno de Nuevo León. (2006). Por un Nuevo León Próspero y de Oportunidades. Recuperado de: http://portal.nl.gob.mx/PED/imagenes / CPVART.doc

Gobierno de Nuevo León. (2006a). Rueda de prensa ofrecida a los medios de comunicación por el C. Jefe de la Oficina Ejecutiva de la Gubernatura. Recu- 
perado de: http://www.nl.gob.mx/?P=leerarticulo\&ArtOrder=Rea $\mathrm{d}$ Art\&Article $=57342$

Gobierno de Nuevo León. (2006b). Clausuran las actividades del mes de Nuevo León en San Antonio. Recuperado de: http://www.nl.gob.mx/?P=leer articulo\&ArtOrder $=$ ReadArt\&Article $=$

Gobierno de Nuevo León. (2006c). Se reúne Gobernador del Estado con el Presidente del Banco Mundial. Recuperado de: http:/ /www.nl.gob.mx/?P= leerarticulo\&ArtOrder $=$ ReadArt\&Article $=53817$

Gobierno del Estado de Nuevo León (2006d). Pormenores de la Agenda de Trabajo del Gobernador José Natividad González Parás en su reciente viaje de dos días a los Estados Unidos de Norteamérica. Recuperado de: http:// www.nl.gob.mx/?P=leerarticulo\&ArtOrder=ReadArt\&Article $=53917$

Gobierno del Estado de Nuevo León (2006e). Expone Gobernador del Estado de Nuevo León a la comunidad Cbina proyecto de la Ciudad Internacional del Conocimiento. Recuperado de: http://www.nl.gob.mx/?P=leerarticulo $\&$ ArtOrder $=$ ReadArt\&Article $=55479$

Gobierno de Nuevo León. (2007). Oficina Ejecutiva de la Gubernatura. Recuperado de: http://www.nl.gob.mx/pics/pages/depen_aux_gob_ edo_base/LibroII_OFGUBERNATURA.pdf

Gobierno de Nuevo León. (2007a). Corporación para el Desarrollo de la Zona Fronteriza de Nuevo León. Recuperado de: http://www.nl.gob. $\mathrm{mx} / \mathrm{P}=$ codefront

Gobierno del Estado de Nuevo León. (2007b). Consulados en el Estado de Nuevo León. Recuperado de: http://www.nl.gob.mx/?P=t_turismo_ consuladosGobierno

Gobierno del Estado de Nuevo León. (2007c). Asuntos Internacionales. Recuperado de: http://www.nl.gob.mx/?P=asuntos_internacionales

Gobierno del Estado de Nuevo León. (2007d). Data Nuevo León. Recuperado de: http:/ /www.nl.gob.mx/?P=datanl

Gobierno del Estado de Nuevo León (2007e). Comunicado deprensa. Encabeza Gobernador del Estado misión de Universidades y empresarios de Nuevo León por China y Japón. Recuperado de: http://www.nl.gob.mx/?P=leerart iculo\&ArtOrder $=$ ReadArt\&Article $=5542$

Gobierno del Estado de Nuevo León. (2007f). Integración económica noreste de México-Texas. Monterrey: Gobierno del Estado de Nuevo León-Fondo Editorial de Nuevo León. 
Gobierno del Estado de Nuevo León. (2007g). Entrevista concedida a los medios de comunicación vía telefónica desde Davos, Suiza, por el C. Gobernador del Estado, Lic. José Natividad González Parás. Recuperado de: http:/ / www.nl.gob.mx/?P=leerarticulo\&ArtOrder=ReadArt\&Article $=56444$

González Parás, J. N. (1978). El fortalecimiento del pacto federal. México: Instituto de Administración Pública.

González Parás, J. N. (1982). Desconcentración, descentralización y división territorial. México: Instituto de Administración Pública.

Hirch, J. (1999). Global capitalism versus democracy in Globalization, Class and the Question of Democracy. New York: Merlin Press and Monthly Review. http:/ /www.sre.gob.mx/eventos/forogoblocales/doc/raquelmor_uag.pdfhttp://www.sre.gob.mx/eventos/forogoblocales/doc/ aquelmor.uag.pdf

Hurrel, A. (1995). Regionalism in world politics. Nueva York: Oxford University Press.

Kennedy, P. (1993). Hacia el siglo XXI. España: Plaza \& Janes Editores.

Keohane, R. O., \& Nye, J. (1989). Power and Interdependence. Nueva York: Scott-Foresman.

Laïdi, Z. (1994). Un mundo sin sentido. México D. F.: Fondo de Cultura Económica.

Lecours, A. (2002). Paradiplomacy: Reflections on the Foreign Policy and International Relations of Regions. International Negotiation Journal, $7(1), 17$.

López F. F. \& Shiavon, J. A. (2005). La política internacional de las entidades federativas mexicanas [Versión electrónica]. Documentos de Trabajo del CIDE, 127. Recuperado de: http://biblioteca.itesm.mx/nav/contenidos_salta2.php?col_id=mty.ciao

Martínez, M. (2007). La paradiplomacia, una alternativa para el acceso a recursos internacionales. Recuperado de: http:/ /www.comercioexterior.ub.es/ tesina/proyectos02-03/martinez_justo_manuel.doc

Maryann, K. C. (1999). Más allá de la soberanía. El surgimiento de los problemas transoberanos. Boston: Bedford/St. Martins.

Montaño, J. (2003). El Senado de la República en la formulación de la Política exterior. En R. Fernández de Castro (Coord.), En la frontera del imperio. México: Ariel-ITAM.

Moreno, R. (2007). La acción exterior de los gobiernos no centrales. Recuperado de: http://www.sre.gob.mx/eventos/forogoblocales/doc/raquel- 
mor_uag.pdfhttp:/ /www.sre.gob.mx/eventos/forogoblocales/doc/ raquelmor_uag.pdf

Ohmae, K. (1997). El fin del estado-nación. Chile: Andrés Bello.

Ohmae, K. (2005). Next Global Stage: The Challenges and Oportunities in Our Borderless World. Pennsylvania: Wharton School Publishing.

Rodríguez, S. (2006). La paradiplomacia: las relaciones internacionales de los gobiernos locales México. México D. F., Miguel Ángel Porrúa.

S/a. Constitución Política de los Estados Unidos Mexicanos, (2005). México: ISEF. Zeraoui, Z. (2007b). La paradiplomacia y la emergencia de la politica internacional de las regiones. Recuperado de: http://biblioteca.itesm.mx/cgi-bin/ doctec $/$ opendoc? cual $=4919 \&$ archivo $=112538 \&$ pagina $=3981 \&$ pagi nas $=3981,2 \&$ query $=($ paradiplomacia $), A N D$, tipo $\% 3 \mathrm{Da}$ 